\title{
Norois
}

Environnement, aménagement, société

206 | 2008/1

Itinéraires de lieux touristiques littoraux

\section{Dynamiques du tourisme le long des côtes atlantiques}

Philippe Violier

\section{CpenEdition}

Journals

Édition électronique

URL : http://journals.openedition.org/norois/205

DOI : 10.4000/norois.205

ISBN : 978-2-7535-1554-3

ISSN : $1760-8546$

Éditeur

Presses universitaires de Rennes

Édition imprimée

Date de publication : 1 mars 2008

Pagination : 7-8

ISBN : 978-2-7535-0690-9

ISSN : 0029-182X

\section{Référence électronique}

Philippe Violier, «Dynamiques du tourisme le long des côtes atlantiques », Norois [En ligne],

206 | 2008/1, mis en ligne le 01 mars 2008, consulté le 20 avril 2019. URL : http://

journals.openedition.org/norois/205; DOI : 10.4000/norois.205

(c) Tous droits réservés 


\title{
Introduction
}

\section{DyNAMIQUES DU TOURISME LE LONG DES CÔTES ATLANTIQUES}

\author{
Philippe Violier \\ ESO CARTA \\ (Université d'Angers), \\ 7 allée François-Mitterrand, BP 40455 - 49004 Angers \\ Philippe.Violier@univ-angers.fr
}

La côte atlantique, dans sa partie nord occidentale a été le premier littoral au monde à être affecté par le tourisme, si l'on retient que le tourisme a été inventé en Angleterre et constitue avec l'invention de la démocratie et avec l'industrie, une des révolutions fondatrices qui au XVIII ${ }^{\mathrm{e}}$ siècle ont accouché de notre modernité (Boyer, 1996; Tissot, 2000; Équipe Mit, 2005) ce qui est discuté (Dewailly, 2006). La diffusion du tourisme à partir de son foyer initial s'est donc réalisée en partie le long de cette côte, si bien que pour la France, les côtes de la Manche, et notamment en Normandie, apparaissent en 1869 (Knafou, 1997), comme la façade littorale la plus fréquentée, que des lieux touristiques plus discontinus émaillent ensuite la côte au sud de la mer bordière, fréquentation attestée aux Sables-d'Olonne dès 1823, à Arcachon dès 1820 par exemples, et que c'est à San Sebastian que la monarchie espagnole prendra ses quartiers d'été dans la seconde moitié du XIX siècle.

Cette diffusion s'est réalisée soit sous la forme de création de lieux ex-nihilo, soit par la transformation d'établissements humains anciens. Depuis ces lieux ont évolué. Ce sont ces dynamiques que ce dossier thématique entend appréhender, et selon deux approches. D’une part les auteurs ont souhaité analyser les changements qui, dans la période récente, ont affecté ces lieux. En effet ces lieux changent, dans un contexte marqué par le passage du tourisme de masse, défini comme la possibilité au sein d'une société de l'accès au tourisme pour le plus grand nombre, soit à partir de $50 \%$, au tourisme de masse personnalisé, marqué par l'affirmation croissante de l'individu au sein des sociétés occidentales (pour le tourisme voir Cuvelier, 1998). Également les pratiques touristiques changent à des rythmes variés et ces évolutions affectent les lieux, en créant de nouveaux ou en favorisant la pérennité des plus anciens (Équipe Mit, 2005). Mais le tourisme n'est pas un objet autonome et l'évolution des lieux touristiques est également influencée par des facteurs qui ne sont pas spécifiques comme l'accroissement de la mobilité et l'évolution des modes d'habiter. Les articles rassemblés ne prétendent pas aborder l'ensemble des dynamiques mais cherchent à en montrer et à en comprendre la diversité (Morice Jean-René, Pébarthe Hélène et Violier Philippe), ou abordent un itinéraire plus spécifique celui qui aboutit à un type original, que l'auteur propose de nommer « communauté vacancière » (Duhamel Philippe). Ensuite Alexandre Magnan montre, à propose de Saint-Martin, comment les jeux d'acteurs induisent des évolutions que l'on peut qualifier de hiératiques.

D'autre part, des auteurs se sont intéressés aux moyens de gérer les dynamiques en cours. Guillaume Nardin, Iwan Le Berre et Louis Brigand exposent ainsi comment un SIG peut permettre d'encadrer le développement d'une pratique de loisir et de tourisme, la plaisance, dont le développement suscite la création d'équipements et entre en conflit avec d'autres fonctions ou d'autres usages du littoral. Enfin, Sébastien Fougnie appréhende l'évolution des politiques d'aménagement mises en œuvre dans les lieux touristiques. 


\section{Bibliographie}

Boyer (M.), 1996. - L'invention du tourisme, Paris, Gallimard, coll. « Découvertes », 160 p.

Cuvelier (P.), 1998. - Anciennes et nouvelles formes de tourisme, Paris, L'Harmatan, coll. "Tourisme et société », 238 p.

Devailly (J.-M.), 2006. - Tourisme et géographie entre pérégrinité et chaos?, Paris, L'harmattan, coll. « Tourismes et sociétés », $221 \mathrm{p}$.

ÉQuipe Mit, 2005. - Tourismes 2. Moments de lieux, Paris, Belin, 349 p.

Knafou (R.), 1997. - Atlas de France, Volume Tourisme Loisirs, Paris, La Documentation Française - Reclus, 109 p.

Tissot (L.), 2000. - Naissance d'une industrie touristique, les Anglais et la Suisse au XIX siècle, Lausanne, Payot, coll. « Histoire », 302 p. 